\title{
Histórias Escondidas nos Mapeamentos Fronteiriços
}

\author{
Agências Indígenas nos Arquivos do Coronel Percy Harrison Fawcett \\ Hidden Histories in Border Mappings: Indigenous Agencies in the Archives of \\ Colonel Percy Harrison Fawcett \\ Historias ocultas sobre el mapeo de fronteras: Agencias indígenas en los archivos \\ del coronel Percy Harrison Fawcett \\ Histoires cachées dans les mappages de frontières: Agences autochtones dans les \\ archives du colonel Percy Harrison Fawcett
}

\section{André Reyes Novaes}

\section{OpenEdition}

Journals

\section{Edição electrónica}

URL: https://journals.openedition.org/terrabrasilis/7124

DOI: 10.4000/terrabrasilis. 7124

ISSN: 2316-7793

Editora

Rede Brasileira de História da Geografia e Geografia Histórica

Refêrencia eletrónica

André Reyes Novaes, «Histórias Escondidas nos Mapeamentos Fronteiriços», Terra Brasilis [Online], 14 | 2020, posto online no dia 31 dezembro 2020, consultado o 05 dezembro 2022. URL: http:// journals.openedition.org/terrabrasilis/7124 ; DOI: https://doi.org/10.4000/terrabrasilis.7124

Este documento foi criado de forma automática no dia 5 dezembro 2022.

All rights reserved 


\title{
Histórias Escondidas nos Mapeamentos Fronteiriços
}

\author{
Agências Indígenas nos Arquivos do Coronel Percy Harrison Fawcett \\ Hidden Histories in Border Mappings: Indigenous Agencies in the Archives of \\ Colonel Percy Harrison Fawcett \\ Historias ocultas sobre el mapeo de fronteras: Agencias indígenas en los archivos \\ del coronel Percy Harrison Fawcett \\ Histoires cachées dans les mappages de frontières: Agences autochtones dans les \\ archives du colonel Percy Harrison Fawcett
}

André Reyes Novaes

\section{NOTA DO AUTOR}

A pesquisa foi realizada com o Apoio da CAPES, por meio do Programa de Professor Visitante no Exterior.

\section{Introdução}

1 No ano de 1905 o então presidente da Royal Geographical Society chamou o militar britânico Percy Harrison Fawcett em sua sala e perguntou: "você conhece alguma coisa sobre a Bolívia"? (Fawcett, 2001: 18). ${ }^{1}$ Após uma resposta negativa, o presidente falou sobre um país que não se limitava às terras altas, conhecidas como "teto do mundo", mas se expandia a Leste por uma enorme área de florestas tropicais e planícies ainda não exploradas. De acordo com a narrativa do coronel Fawcett, o presidente pegou um grande Atlas ao lado da sua mesa e, apontando para a região amazônica, falou: "olhe para essa área! É cheia de espaços em branco porque tão pouco é conhecido" (Fawcett, 2001: 18). A área era a região de fronteira entre a Bolívia, o Peru e o Brasil, onde o mapeamento de muitos rios não passariam de um trabalho de suposição, um guesswork, ${ }^{2}$ 
nas palavras do presidente. Apesar de desconhecida e pouco mapeada, a região teria um grande potencial econômico, pois o "fantástico preço da borracha" teria atraído novos contingentes populacionais e intensificado a disputa na demarcação dos limites internacionais.

2 Ao escutar sobre as fronteiras, Percy Fawcett interrompeu a explicação, "só um minuto", "tudo isso é muito interessante, mas o que tem a ver comigo?" (Fawcett, 2001: 19). O presidente foi direto ao ponto. O governo da Bolívia, pelos seus representantes diplomáticos em Londres, teria solicitado à Royal Geographical Society a recomendação de um militar experiente para o trabalho na comissão boliviana: "Como você completou o nosso curso de delimitação de fronteiras com muito sucesso, eu pensei prontamente em você" (Fawcett, 2001: 19). Foi a partir desse convite que Percy Fawcett fez sua primeira viagem para a América do Sul, para atuar como chefe da comissão Boliviana de limites. Entre 1906 e 1925, quando desapareceu em busca de uma cidade perdida no território brasileiro, o militar participou de uma série de mapeamentos na região amazônica, que teriam auxiliado na resolução de conflitos relativos à demarcação dos limites.

3 A história de Fawcett é bastante conhecida por meio de uma vasta produção literária, que tem início com a publicação dos relatos do explorador por seu filho Brian Fawcett em 1953 (Fawcett, 2001). Como único filho sobrevivente, já que Percy Fawcett havia levado seu filho mais velho para sua última exploração no interior do Brasil, Brian ficou com todos os documentos do pai e publicou trechos de seus relatos ilustrados por desenhos e fotografias. Nas décadas seguintes muitos trabalhos ficcionais utilizaram esta publicação como ponto de partida para construir histórias sobre a misteriosa cidade Z, que, segundo Fawcett, estaria localizada próximo ao estado do Mato Grosso. Essas obras ficcionais, por sua vez, estimularam uma série de produções audiovisuais, tendo como exemplo mais famoso o filme A Cidade Perdida de Z, lançado em 2017. ${ }^{3}$ Nas entrevistas com o elenco do filme fica bastante evidente a sobrevivência de uma cultura celebratória da exploração em pleno século XXI (Driver, 2001). Atores e autores repetem de forma cíclica uma narrativa sobre os últimos "espaços vazios nos mapas", onde Fawcett teria se aventurado com um "propósito quase divino". ${ }^{4}$ Se Cook cartografou o Pacífico e Livingstone explorou o vasto continente africano, Fawcett teria preenchido espaços em branco na Amazônia, região apresentada como a "última área selvagem". ${ }^{5}$ 
Figura 1. Percy Fawcett com o Teodolito

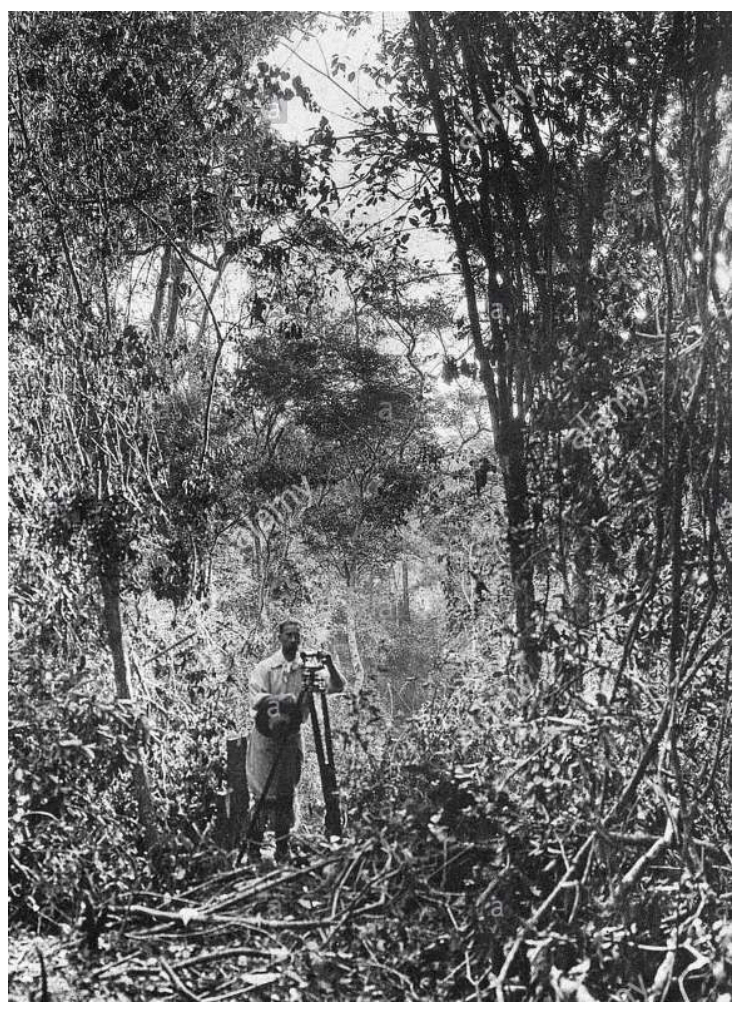

Fonte: Arquivos da Royal Geographical Society. Referência 058339. "Forest near Corumba". Disponível em: https://www.alamy.com/stock-photo/percy-fawcett.html

4 Muitas imagens poderiam corroborar com essas narrativas heroicas. Como a fotografia de Fawcett mapeando espaços desconhecidos com o seu teodolito no meio da floresta amazônica (Figura 1). o grande explorador com seus instrumentos, desbravando de forma solitária um espaço vazio para colocá-lo no mapa. Mas, para além dessas narrativas populares e míticas, ainda são raros os trabalhos acadêmicos que buscam colocar os arquivos do explorador em diálogo com abordagens pós-coloniais e decoloniais contemporâneas, vigentes em campos variados como a geografia histórica (Radcliffe, 2017), a história da cartografia (Craib, 2017) e a história das ciências (Raj, 2006). Ao mergulhar nos arquivos com lentes críticas e menos celebratórias, algumas questões ganharam centralidade para estudar as práticas das explorações: quem acompanhava Fawcett? Quais técnicas e práticas cartográficas foram aplicadas nos seus mapeamentos? Qual foi o papel da troca de conhecimento na produção cartográfica sobre estes espaços "desconhecidos"?

5 Como apresentado em romances e produções audiovisuais, o explorador nomeou alguns ajudantes em seus relatos, como o britânico Mr. Fisher, que o acompanhou tanto na jornada do Alto Acre como no mapeamento do Rio Verde. Mas, embora na maioria das fotografias Fawcett apareça acompanhado de instrumentos ou poucos ajudantes, a agência indígena na exploração também aparece de forma constante em suas imagens e relatos. Um número bem maior de participantes das expedições aparece nos registros de transição das bacias hidrográficas, quando era necessário carregar as embarcações por terra. Além disso, Fawcett descreve a presença de ajudantes de diferentes etnias indígenas em seus relatos. Ao deixar Riberalta para explorar o Rio Beni até as nascentes do Abuña, em 25 de setembro de 1907, Fawcett relatou, por exemplo, como estava 
acompanhado de um grupo com "dez índios Ixiamas e oito Tumupasa, um timoneiro e um jovem do exército para servir como intérprete" (Fawcett, 2001: 58). A presença constante dos índios, sejam hostis ou colaborativos, evidencia como, diferentemente de um "espaço vazio", as fronteiras amazônicas continham uma diversidade populacional com um vasto conhecimento sobre o território.

6 Foi com o objetivo de estudar os arquivos de Percy Harrison Fawcett com uma abordagem menos celebratória, eurocêntrica e colonialista que submeti um projeto para pesquisar os documentos disponíveis na Royal Geographical Society e nos National Archives. ${ }^{6}$ Ao obter a bolsa de estudos tive a oportunidade de me aprofundar nos mapas, cartas, fotografias e cadernetas de campo do explorador. Este texto propõe um primeiro ensaio para uma abordagem crítica destes arquivos, buscando vestígios de trocas de conhecimento e encontros cartográficos que possibilitem identificar, nas palavras e imagens do explorador, a agência e as práticas de atores silenciados nas narrativas hegemônicas sobre as explorações geográficas.

7 Na primeira seção, gostaria de delinear algumas inspirações metodológicas que estimularam a formulação do projeto. Dois grupos bastante díspares de autores povoavam as minhas leituras no momento de concepção da pesquisa sobre Percy Harrison Fawcett. Por um lado, eu retomava a leitura do trabalho de alguns geógrafos históricos, que desde o final da década de 1990 abordam sistematicamente o desafio de revisitar os arquivos em busca de "histórias escondidas da exploração" (Driver e Jones, 2009; Konishi et al., 2015). Por outro, a leitura de autores associados ao pensamento social brasileiro nos anos 1940 também evidenciava uma intensa preocupação com o papel dos indígenas e "mamelucos" nos processos de exploração e mapeamento (Holanda, 1947; Cortesão, 2009). Pesquisando em contextos completamente diferentes, estes autores se depararam com questões bastante similares diante dos arquivos, selecionando fragmentos de amplos universos documentais para evidenciar trocas de conhecimento nos processos de exploração e mapeamento.

8 Após este breve apanhado sobre o percurso metodológico, a seção seguinte explora alguns fragmentos selecionados neste mergulho ainda raso e incipiente nos arquivos de Percy Fawcett. Para não me perder no mar agitado dos documentos, selecionei como farol um caso bastante pontual, considerando as práticas de mapeamento nas primeiras explorações amazônica de Fawcett na bacia do rio Acre entre os anos de 1906 e 1907. Tendo como principal objetivo localizar as nascentes do Rio Abuña para atender as delimitações estabelecidas no tratado de Petrópolis, assinado entre Brasil e Bolívia em 1903, a exploração buscava cobrir todo o Rio Acre e produzir uma nova cartografia da região. Estes foram os primeiros mapas feitos por Fawcett com que me deparei nos arquivos, mas as escassas referências ao processo de mapeamento nas cartas do explorador me deixaram apreensivo. Aos poucos, as trocas de conhecimento foram se revelando em diferentes fragmentos dos arquivos, sugerindo que, além de um explorador que mapeou espaços desconhecidos com técnicas científicas objetivas, Fawcett também utilizava a suposição e a coleta de informações locais como prática constante no mapeamento das fronteiras amazônicas.

\section{Os Arquivos e suas Histórias Escondidas}

9 A primeira vez que entrei no prédio da Royal Geographical Society, em Londres, para observar documentos sobre explorações geográficas foi em 2009, durante o estágio 
doutoral que fiz na Royal Holloway University. Justamente naquele ano, mais precisamente entre 15 de outubro e 10 de novembro, o meu orientador externo, Felix Driver, em colaboração com a geógrafa Lowri Jones, organizavam uma exposição chamada História Escondidas da Exploração [Hidden Histories of Exploration], fruto de uma ampla pesquisa nos arquivos da instituição. ${ }^{7}$ Logo no início da exposição, os autores deixavam evidentes as suas intenções. Contrastando com uma abordagem que transforma a exploração em um "drama individual", ocorrido em "circunstâncias extraordinárias", os autores destacavam que as explorações foram uma experiência necessariamente coletiva e que envolviam muitas pessoas em uma série de relações. "Nós precisamos abrir espaço em nossas histórias para parceiros, guias, carregadores, fixadores, intérpretes, comerciantes e funcionários que faziam possíveis as viagens de exploração" (Driver e Jones, 2009: 5). Além disso, também seria necessário estudar patrocinadores, patronos, editores e editoras que possibilitaram a circulação ampla das informações dessas viagens.

10 Eu me recordo de ler atentamente os textos introdutórios da exposição e, ao circular pelos painéis, deparei-me pela primeira vez com o nome de Percy Fawcett. Em meio a uma série de exemplos, os autores citam a exploração ao Mato Grosso, realizada em 1925 por George Diott, que tinha o objetivo de encontrar o Coronel Fawcett, desaparecido na região. Eu nunca havia escutado aquela história e a exploração de Diott mostrava uma colaboração vital com os índios do Xingu. Ao explorar os seus diários e fotografias, Driver e Jones (2009) destacaram a presença constante de um índio Bakairi, chamado de Bernardino nos documentos. A "dependência europeia" dos conhecimentos locais fica evidente nas atividades ordinárias da exploração: busca por alimento e abrigo, mobilidade, transporte e orientação. Ao ver as fotografias tiradas por Diott do "seu" índio carregando as bagagens da expedição pelo alto Xingu, a narrativa de um trabalho solitário e heroico se desmonta instantaneamente. Essas imagens e textos certamente contribuíram para despertar em mim um interesse renovado pela história das explorações do território brasileiro.

11 Uma outra imagem, que também chamou bastante minha atenção durante a exposição, foi a litografia representando os "hidrógrafos" Inuit, chamados de "Ikmalick and Apelagliu" (Figura 2). Esses nativos do Ártico teriam abordado o navio comandado por John Ross, que buscava uma passagem Norte-Oeste pelo norte do Canadá em 1830 . Na imagem, litografada a partir dos diários do próprio capitão Ross, os nativos desenham um mapa dentro da cabine do navio, protagonizando um exemplo explícito de exploração geográfica enquanto transferência de conhecimento (Lefebvre e Surun, 2008) . A exposição proporcionou, assim, uma série de exemplos sobre como é possível explorar histórias escondidas e agências indígenas em arquivos dedicados a "grandes exploradores", utilizando técnicas visuais para mostrar “inversão de papeis", "justaposições" e produzir um "re-escalamento" da visibilidade dos agentes envolvidos nas explorações (Driver, 2013). Na época, estudando representações sobre a história das fronteiras brasileiras, pareceu-me bastante promissor estudar as relações de conflito e colaboração entre as populações indígenas e as comissões de limites no mapeamento das fronteiras sul-americanas. No entanto, não era prudente modificar meu objeto de estudos naquela altura do campeonato, e segui em frente com minhas pesquisas sobre cartografia, fronteiras e imprensa no século XX. 
Figura 2. 'Ikmalick and Apelagliu' J. Brandard, John Ross, 1835 (cat. no. 6)



Fonte: Arquivos da Royal Geographical Society. Referência rgs332736. Ross, John, Sir, (1777-1856) e Ross, James Clark, Sir, (1800-1862) - "Narrative of a second voyage in search of a north-west passage, and of a residence in the Arctic regions during the years 1829, 1830, 1831, 1832, 1833". Disponível em: https://www.rgs.org/about/our-collections/online-exhibitions/hidden-histories-ofexploration/

12 Alguns anos mais tarde, fui tatear novos temas de pesquisa sobre história da cartografia e me deparei novamente com a temática da agência indígena nas explorações e mapeamentos. Ao ler o livro póstumo do historiador português Jaime Cortesão (2009), História do Brasil nos Velhos Mapas, eu esperava encontrar uma visão historiográfica colonialista portuguesa, que exaltasse grandes heróis lusitanos responsáveis por explorar e mapear o território brasileiro. 0 trabalho de Cortesão, de fato, privilegia a agência portuguesa e atribui o sucesso da expansão territorial do Brasil, tanto aos exploradores, que avançavam no terreno, quanto à Coroa e sua diplomacia, que estimulavam o movimento através de mitos como a Ilha-Brasil. Cortesão foi fundamental na difusão da ideia de que o Brasil herdou uma "ossatura" territorial dos portugueses, que tiveram habilidades e intencionalidades na ocupação do território. No entanto, apesar da narrativa lusitana, foi interessante observar como em muitas passagens a agência indígena é destacada como fundamental para as práticas de exploração e mapeamento.

Considerando o mapeamento das fronteiras que sucedeu os tratados de Madrid (1750) e San Idelfonso (1777), por exemplo, Cortesão revela que muitas cartas tiveram "longos trechos de rio, feitos exclusiva e declaradamente por informações indígenas" (Cortesão, 2009: 53). Essa afirmação tem sido reforçada por pesquisas contemporâneas que evidenciaram como esses mapeamentos se deram em meio a uma sobreposição de múltiplas territorialidades e práticas representacionais. Ao pesquisar os conflitos e trocas de conhecimento no estabelecimento dessas fronteiras imperiais em arquivos de diferentes países, estudos recentes têm revelado como agentes nativos cobravam impostos, mostravam caminhos e muitas vezes moldaram quando e onde a fronteira foi desenhada (Erbig Jr., 2020). 

explorações geográficas brasileiras. Desde que chegou ao Brasil exilado de Portugal, em dezembro de 1940, Cortesão se interessou por documentos que revelassem as trocas de conhecimento entre indígenas e exploradores, e esta temática foi abordada por ele em palestras $(1944)^{8}$ e artigos de jornal (1947-8). Os textos publicados na imprensa, como $O$ Índio: Bussola e Mapa Vivo (Cortesão, 1947) e Origens Indígenas do Mito da Ilha-Brasil (Cortesão, 1948), foram incorporados posteriormente no seu livro e ajudaram a inserir Jaime Cortesão em debates historiográficos sobre técnicas indígenas de mapeamento e exploração (Ribeiro, 2018; Novaes 2020).

O principal interlocutor de Cortesão sobre a agência indígena nos arquivos históricos da exploração foi o historiador brasileiro Sérgio Buarque de Holanda. Apesar de divergirem publicamente sobre a polêmica criada em torno do mito da Ilha-Brasil, pois Holanda contestou a tese do historiador português em artigos de jornal (Holanda, 1952) e livros (Holanda, 2010), é interessante identificar como existe uma convergência no reconhecimento da agência indígena na exploração e mapeamento do território brasileiro. A relação e influência-mútua entre esses historiadores vem sendo estudada de forma aprofundada em investigações contemporâneas (Oliveira, 2013; Ribeiro, 2018; Novaes, 2020). Muitas alfinetadas e discordâncias foram destacadas nos seus textos pelos comentadores contemporâneos, mas quando o tema é agência indígena, os autores parecem compartilhar grande parte das referências e conclusões.

No capítulo dedicado aos Aborígenes e suas relações com a Terra, publicado no livro História do Brasil nos Velhos Mapas, Cortesão (2009: 56) elogia o "notabilíssimo" estudo de Holanda publicado em 1949, chamado Índios e Mamelucos na expansão paulista. Cortesão alega que teria escrito "simultaneamente e independentemente" sobre a mesma temática que o historiador brasileiro e destaca seu envolvimento com o assunto desde 1944. No entanto, a coincidência nas referências e documentos citados por ambos não deixa dúvida que os autores sofreram influências recíprocas. Cortesão teve em Holanda uma inspiração fundamental para o seu interesse pelas técnicas indígenas de deslocamento, proteção, alimentação e representação do espaço. Da mesma forma, o brasileiro também pode ter absorvido muitas informações e referências nas palestras e escritos anteriores de Cortesão. Independentemente do pioneirismo sobre a temática, é notório que os autores utilizaram referências e documentos similares, como as expedições de Alexandres Rodrigues Ferreira (1783), Von den Steinen (1886) e Theodor Koch-Grünberg (1909).

17 Alexandre Rodrigues Ferreira, em exploração no Alto Paraguai, conta que, ao perguntar sobre os afluentes do rio Branco a um índio, ele tomou uma corda de piça, "com a qual formou o tronco principal do rio, a um outro lado foi prendendo tantos filamentos quantos os seus tributários, dando-lhes as voltas e as distâncias próprias uns dos outros, e, por fim, tantos nós quantas as aldeias de índios nas posições respectivas e em todos esses cursos" (Cortesão, 2009: 55). Theodor Koch-Grünberg, por sua vez, "viu um Tauripã desenhar o curso completo do Cuquenáu com seus setenta afluentes, bem como o perfil das serras de Roraima e Cuquenáu" (Holanda, 1949: 182). Mas o explorador mais citado, tanto pelo historiador português quanto pelo brasileiro, foi Von den Steinen, que "orientou a segunda das suas expedições às nascentes do Xingu, em 1887-1888, por uma carta de um índio" (Cortesão, 2009: 53).

Os mapas presentes na obra de Steinen (Figura 3) fizeram com que Cortesão e Holanda a concordassem sobre a existência de uma "cartografia indígena" (Holanda 1949: 183), 
que teria originado uma linguagem visual com forte ênfase na função comunicativa. Holanda (1949) identifica uma série de práticas representacionais que permitiriam um "aproveitamento rigoroso da experiência anterior, em esquemas onde tudo visa a utilidade" (Holanda, 1949: 183; Cortesão, 2009: 55). As cachoeiras representadas com uma "linha quebrada" e os rios representados por uma figura que mais parece um "saca-rolhas" (Holanda, 1949: 182) não pretendem exercer uma função mimética reproduzindo "todas as sinuosidades do curso", mas "tão somente indicar sua irregularidade extrema e com isso acautelar o viajante inexperiente" (Holanda, 1949: 183).

Figura 3. Mapa indígena reproduzido por Von den Steinen (1886: 214)

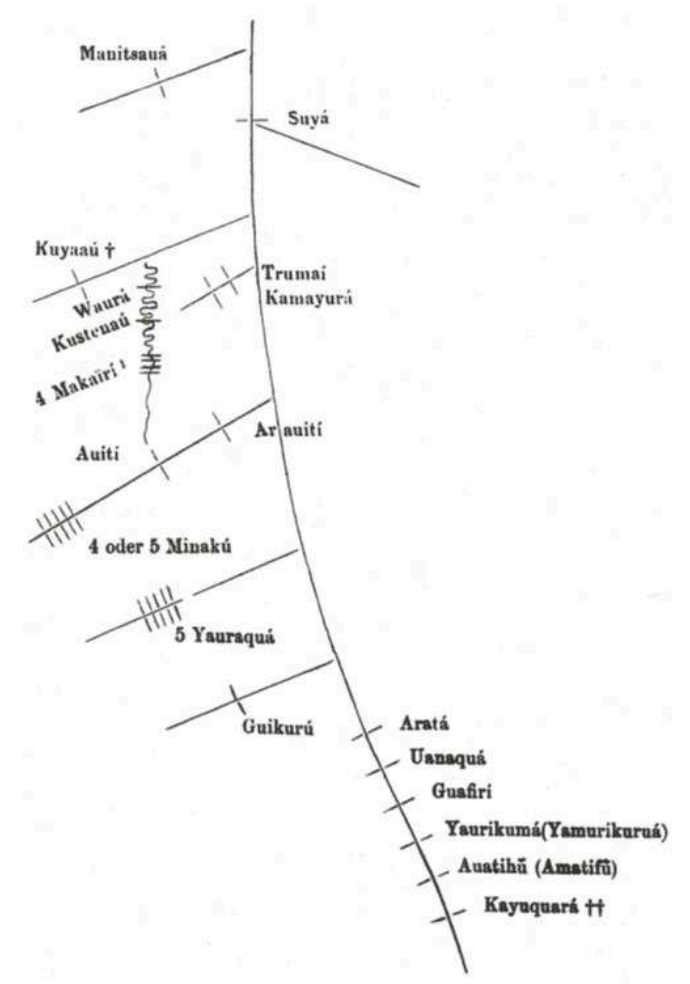

Fonte: Karl von den Steinen (1886). Durch Central-Brasilien. Expedition. Zur Erforschung des Schingú. F. A. Brockhaus, Leipzig. Disponível em: https://digital.bbm.usp.br/handle/bbm/629

19 As fontes e conclusões desses autores me despertaram muito interesse e abriram novos horizontes para o estudo da função comunicativa dos mapas de explorações (Novaes 2020). Mesmo em um contexto histórico e geográfico completamente diferente, os procedimentos e argumentos de Cortesão e Holanda pareciam dialogar com as abordagens de geógrafos históricos contemporâneos. A intenção de identificar, nas palavras e imagens dos exploradores, as ações e performances desempenhados por outros agentes, parece conectar trabalhos produzidos com contextos, documentações e abordagens distintas. $O$ mergulho nos arquivos em busca de vestígios de trocas de conhecimento e agências locais é um desafio metodológico que atravessou inúmeras disciplinas e áreas do conhecimento, sendo uma prática instigante, mas frequentemente exaustiva para pesquisadores interessados nas "histórias dos vencidos" (Leon-Portilla, 1964). ${ }^{9}$ 
O enfoque nas trocas de conhecimento durante a produção cartográfica das comissões de limites do início do século XX pode, à primeira vista, parecer um terreno estéril, pois este período é geralmente associado ao triunfo de uma cartografia científica sobre os "últimos territórios não mapeados". Mesmo considerando que a cartografia não "chegou pronta" da Europa para mapear as Américas, pois sua modernidade se constituiu em concomitância com processos de colonialidade e transferência de conhecimento (Raj, 2006; Mignolo, 2006), o início do século XX parece ser um período marcado pela presença de novos procedimentos, instrumentos e técnicas que modificaram as práticas de mapeamento. A aplicação dessas técnicas poderia, supostamente, reduzir os registros das trocas de informação com a população local, tornando os arquivos das comissões de limite uma descrição monótona de procedimentos e coordenadas numéricas. Acreditando que os arquivos de Percy Fawcett continham mais do que um relato sobre aplicação de instrumentos e técnicas, voltei a Londres para pesquisar nos National Archives e na Royal Geographical Society.

\section{Vestígios Indígenas nos Arquivos de Percy Fawcett}

21 Ao chegar nos National Archives resolvi iniciar a pesquisa por uma pasta que tinha o nome do personagem estudado: F.0 743 Percy Fawcett. A pasta reunia os documentos do Ministério das Relações Exteriores sobre Fawcett e era secreta até 1983. Apesar de parecerem muito promissores, os arquivos consultados não ajudaram de maneira significativa na pesquisa, pois eram majoritariamente concentrados em questões diplomáticas associadas ao sumiço de Fawcett. Uma série de reportagens e cartas diplomáticas oferecem um dossiê riquíssimo sobre o desaparecimento de Fawcett, mas pouco contribuíam para a minha busca por documentos associados às primeiras expedições e mapeamentos fronteiriços do explorador britânico na América Latina. Após coletar alguns mapas interessantes, que evidenciavam a instabilidade das fronteiras durante o período estudado, ${ }^{10}$ resolvi mudar a estratégia e mergulhar nos arquivos da Royal Geographical Society.

Desde o planejamento da pesquisa no Brasil, um grupo de 11 mapas classificados no catálogo como "coleção de mapas do Major Fawcett" (1907 - 1910) me chamava a atenção. Ao chegar nos arquivos esse foi o primeiro grupo de documentos que solicitei ao bibliotecário, que foi buscar o material enquanto eu aguardava em uma mesa comprida no subsolo do prédio. Quando vi um envelope de aproximadamente um metro e meio sendo trazido por um carrinho, compreendi a necessidade de uma mesa tão ampla. Os mapas tinham tamanhos variados, mas alguns chegavam a medir 81 centímetros de altura e 112 de comprimento, ${ }^{11}$ como o mapa Exploration of the River Heath, 1910. Nesta seção, serão explorados dois mapas feitos por Fawcett em 1907 ambos elaborados como resultado de suas primeiras expedições na função de presidente da comissão de limites na Bolívia (Figura 4 e Figura 5): 1) o mapa Bolivia: Fronteira del Norte, que media aproximadamente 36 centímetros de altura e 76 de comprimento ${ }^{12}$ e representava a junção do Abuña com o Madeira; 2) o mapa "Alto Acre", que não tem suas dimensões definidas no arquivo e representa os tributários do rio Acre em direção à cabeceira. Esses dois mapas, escritos em espanhol e assinados por Fawcett enquanto "engenheiro da comissão de limites", tinham o objetivo de atender as demandas iniciais do Governo boliviano, que negociava com o Brasil a delimitação dos acordos definidos no tratado de Petrópolis em 1903. 
Figura 4. Bolivia: La Frontiera del Norte. Percey Fawcett, 1907

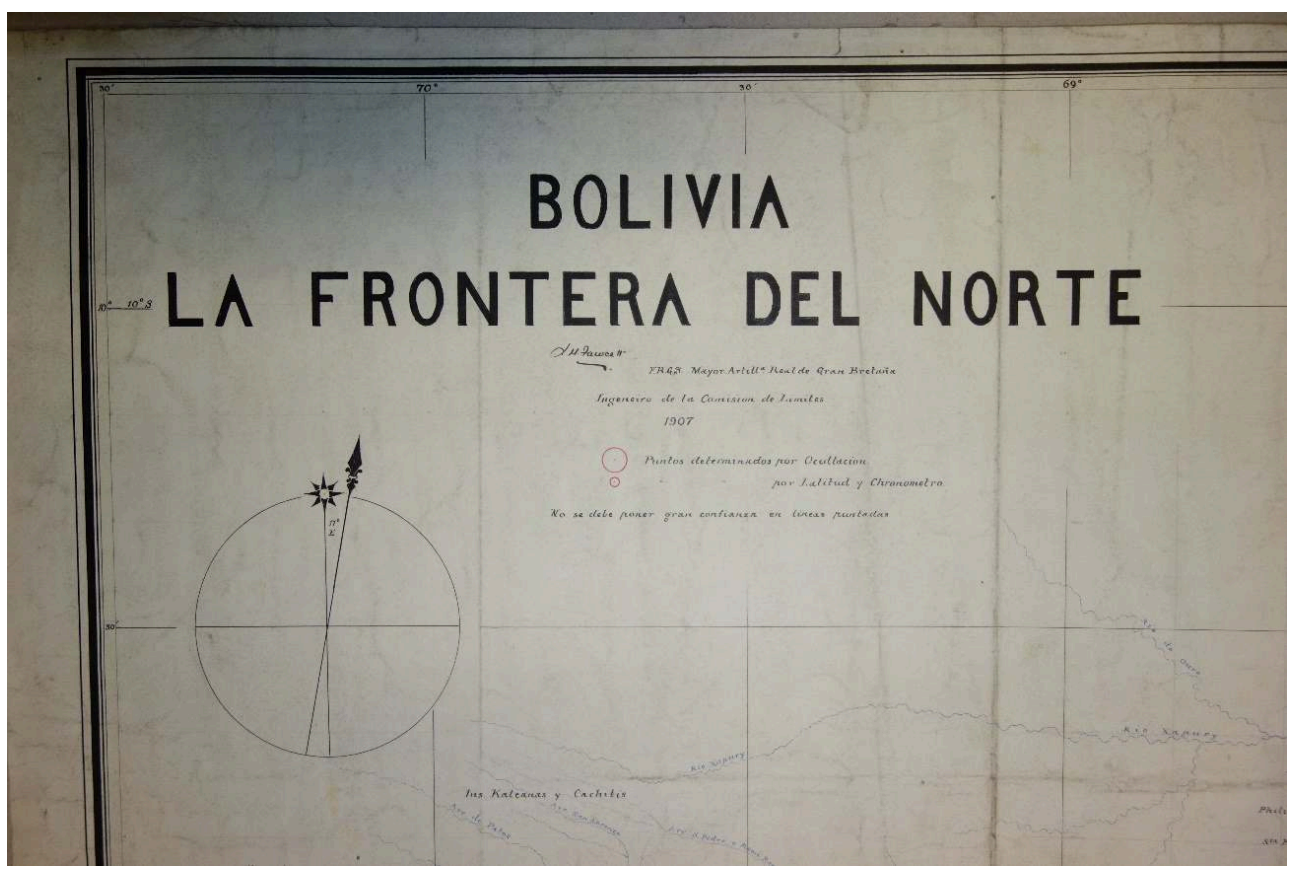

Fonte: Arquivos da Royal Geographical Society. Referência: rgs5617451 (mr Bolivia S.3). Escala 1:735.000. Publicado em La Paz. A. Ballivian, 1907

Figura 5. Alto Acre. Percy Fawcett, 1907

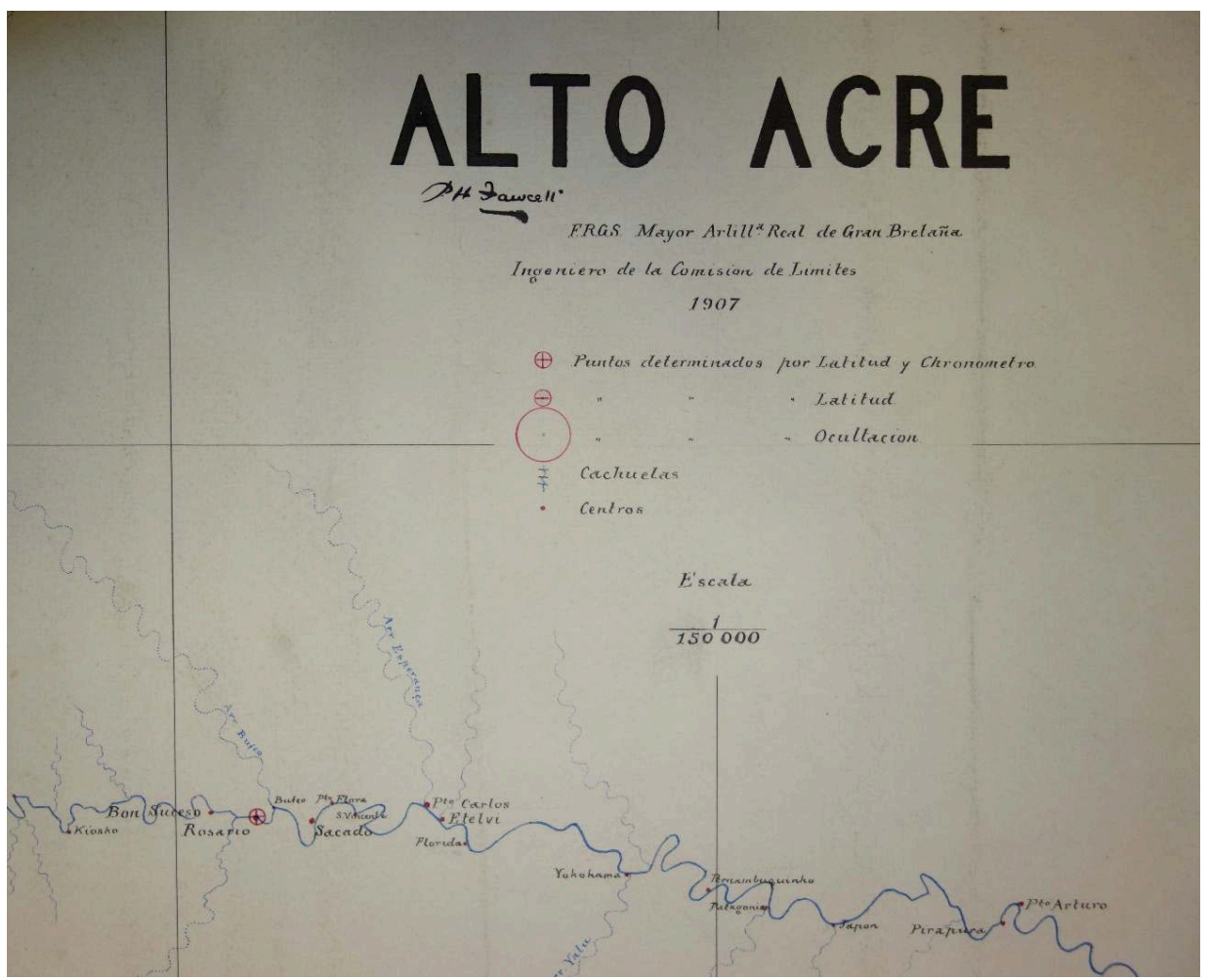

Fonte: Collection of maps by Maj. P. H. Fawcett F.R.G.S, 1907-1910. Referência rgs561156. Escala 1:150 000, embora na ficha tenha escrito uma informação cartográfica: "escalas diferem" 

sobre delimitação fronteiriça, a pesquisadora britânica Rose Mitchell (2020) identificou diferentes etapas nos processos de negociação e demarcação. A primeira etapa é o tratado, que, a partir de mapas mais antigos e menos precisos, delimita as linhas gerais da demarcação fronteiriça. Posteriormente, tem-se a demarcação no terreno, o que geralmente pressupõe a existência de uma comissão mista de limites. Essa exploração e demarcação origina um novo mapa, que apresentaria maior precisão por ser elaborado no terreno a partir de uma série de técnicas e instrumentos. No caso de Fawcett, os objetivos das suas expedições estavam geralmente associados a pontos inconsistentes do Tratado de Petrópolis (1903). Ao percorrer o terreno, o explorador buscava produzir inscrições como mapas e listas de latitude e longitude para ajudar o governo boliviano nas negociações com o Brasil.

A exploração de Fawcett pelo Rio Acre, que durou nove meses entre 1906 e 1907, tinha o intuito de explorar e mapear a parte superior do Rio Acre e determinar as nascentes dos Rios Iquiry e Rapirran (Fawcet, 1909). Esses rios foram apontados como referências fundamentais para o traçado dos limites internacionais no $6^{\circ}$ parágrafo do Tratado de Petrópolis (1903): “da nascente principal do Rapirran, irá pelo parallelo da nascente, encontrar a oeste o Rio Iquiry e subirá por este até a sua origem, donde seguirá até o Igarapé Bahia pelos mais pronunciados accidentes do terreno ou por uma linha recta, como aos Commissarios demarcadores dos dois paizes parecer mais conveniente" ${ }^{13}$ No entanto, a missão de "subir até a origem" do Rio Iquiry não era uma tarefa tão simples e nenhuma comissão fronteiriça tinha estabelecido marcos anteriores em tal localidade. Viajando desde La Paz, Fawcett cruza o altiplano andino e chega a Rurenabaque, região de floresta que, apesar da curta distância, seria "mais remota do que a Inglaterra" (Fawcett, 2001: 43). Para seguir na floresta, Fawcett e seus companheiros formam uma tripulação que incorporou de "dez à vinte e quatro índios" (Fawcett, 2001: 45) e a presença indígena aparece constantemente em sua narrativa.

O trabalho de exploração era feito basicamente com técnicas de navegação indígena, subindo com barcos e canoas que tinham de ser carregados para subir as cachoeiras e cruzar as bacias hidrográficas. 0 trabalho de remar, carregar as embarcações e orientar as direções desses percursos era feito basicamente pelos indígenas, como o próprio Fawcett registrou em suas fotos onde as pesadas embarcações eram levadas por grandes grupos de índios. ${ }^{14}$ Tal prática fazia com que muitas vezes os índios decidissem os limites e rumos da expedição. Após cruzar a Cascata de Avispas na exploração do Alto Acre, a comissão encontra um trecho do rio com uma série de corredeiras e cachoeiras. De acordo com Fawcett, "foi um trabalho árduo subir o riacho, pois transpusemos nada menos que cento e vinte corredeiras e cataratas, com cerca de três ou quatro pés de altura, e as pesadas canoas escavadas tiveram de ser arrastadas e içadas sobre elas" (Fawcett, 2009: 73). Após um grande esforço, as canoas não podiam mais ser levadas e Fawcett declara que gostaria de ter seguido a pé até a nascente do rio, mas "a tripulação indígena recusou-se a continuar e tive medo de deixá-los para trás com as canoas, pois eles poderiam fugir e nos deixar encalhados" (Fawcett, 2001: 73). A "dependência europeia" mencionada na exposição de Driver e Jones (2009) aparece de forma bastante evidente nesse caso. Sem os indígenas a expedição não poderia nem avançar em direção à nascente, nem retornar ao seu ponto de origem.

Ao observar o mapa produzido por Fawcett nessa expedição, o primeiro elemento que me chamou a atenção foi a forma de representação das cachoeiras, que reproduziam 
exatamente a linguagem mencionada por Von den Steinen e debatida por Jaime Cortesão (2009) e Sérgio Buarque de Holanda (1949). As cachoeiras são representadas por uma série de "linhas cortadas" e esses símbolos claramente carregam uma função comunicativa, pois a quantidade de traços acima da Cascata de Avispas não buscava representar mimeticamente os mais de cem obstáculos relatados por Fawcett, mas apenas indicar que o caminho entre esta queda e a cascata dos Ingleses seria repleto de acidentes, o que dificultou o avanço da comissão (Figura 6). Talvez ainda seja muito prematuro, ou mesmo irresponsável, afirmar que esta forma de representação das cachoeiras, incorporada na legenda do mapa de Fawcett (Figura 7), tenha origem em uma linguagem cartográfica indígena sistemática e articulada. No entanto, essa prática evidencia, no mínimo, como o trabalho cartográfico do explorador ia além da aplicação técnica de uma série de instrumentos. O trabalho de suposição, ou guesswork, e a coleta de informação local, também seriam partes integrantes de um amplo espectro de técnicas que possibilitaram a produção dos mapas de Fawcett.

Figura 6. Alto Acre. Percy Fawcett, 1907



Fonte: Collection of maps by Maj. P. H. Fawcett F.R.G.S, 1907-1910. Referência rgs561156. Escala 1:150 000. Detalhe entre as cascatas de Avispas e dos Ingleses

Figura 7. Alto Acre. Percy Fawcett, 1907



Fonte: Collection of maps by Maj. P. H. Fawcett F.R.G.S, 1907-1910. Referência rgs561156. Escala 1:150 000. Detalhe da legenda evidencia a forma de representação das "cachuelas" 
O reconhecimento da suposição como uma prática cartográfica não significa que Fawcett não tenha aplicado uma série de técnicas e instrumentos, principalmente no trabalho de mensuração das longitudes. Tanto nas tabelas da sua caderneta de campo (Figura 8) como nas legendas dos seus mapas (Figura 7), é possível constatar a aplicação de uma série de técnicas como "triangulações", "travessias geodésicas", "observações telegráficas", "diferenças cronométricas" e "ocultação". Mas, apesar de as técnicas aparecerem com destaque no mapa, os relatos de Fawcett evidenciam a extrema dificuldade que o explorador teve para conseguir instrumentos e utilizá-los de forma apropriada no campo. A dificuldade de utilizar instrumentos "universais" e "calibrálos" em diferentes partes do mundo vem sendo destacada por muitos geógrafos históricos contemporâneos, preocupados com uma geografia dos instrumentos (MacDonald e Withers, 2015). Essa temática não será aprofundada neste trabalho, mas é interessante notar como a narrativa de Fawcett revela uma série de gargalos na obtenção e transporte dos instrumentos, o que pode explicar o uso de uma série de técnicas alternativas na obtenção das longitudes.

Figura 8. 'The exploration of the river Aquiry, 1906-7'. Astronomical observations, Bolivia-Peru boundary and Bolivia-Brazil boundary, 1908-10

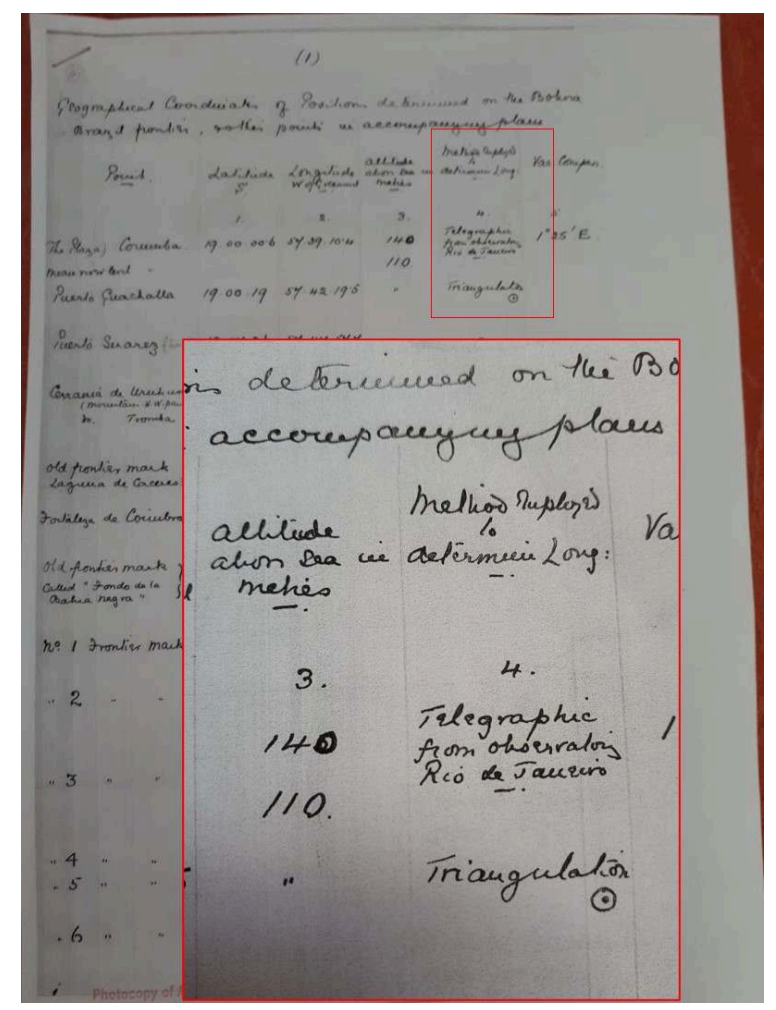

Fonte: The Fawcett Collection. Arquivos da Royal Geographical Society

A ansiedade com os instrumentos, ou a falta deles, aparece na narrativa de Fawcett já em Rurenabaque, muitos antes de chegar ao rio Acre. "Você não precisa se preocupar com eles", disse um Coronel Boliviano, "eles estarão prontos para você em Riberalta, General Pando está lá, e ele os tem” (Fawcett, 2001: 44). Após uma jornada de 22 dias, o grupo de Fawcett chegou a Riberalta em 28 de agosto 1906 e o explorador conheceu o General Pando, ex-presidente da República e Delegado da Província do Beni (Fawcett, 2001: 51). Foi a partir de conversas com o general que Fawcett decidiu o trajeto de sua 
expedição de mapeamento, iniciando pela seção do Acre para retornar a Riberalta antes de se dirigir para a seção do Abuña, onde estavam as nascentes do Iquiry e Rapirran. No entanto, apesar do auxílio da experiência do general, nenhum instrumento aguardava Fawcett em Riberalta e estes deveriam ser coletados em Bahía ou Cobija. Chegando em Cobija, Fawcett ainda não tem acesso aos instrumentos como desejava: "não havia cronômetros, pois um havia sido roubado e o outro estava em Manaus para concerto [sic]. O único teodolito estava muito danificado e não podia ser usado" (Fawcett, 2001:62). Fawcett conclui, portanto, que o trabalho de mapeamento, "uma questão importante se não vital para a Bolívia", seria realizado apenas com "meu próprio sextante e relógio de cronometro [sic]" (Fawcett, 2001: 62).

A limitação no uso dos instrumentos fica evidente nos mapas de Fawcett quando observamos o reduzido número de pontos em vermelho plotados com alguns dos métodos descritos na legenda (Figura 9). Na sua tabela, muitas colunas de longitude são descritas como "indeterminadas" ou "deduzidas" por meio de uma série de outros marcos de fronteira mensurados por comissões anteriores. A informação limitada sobre as coordenadas e cursos de muitos rios levaram Fawcett a utilizar um recurso bastante recorrente nos mapeamentos exploratórios, aplicando linhas pontilhadas para desenhar cursos hidrográficos "supostos". Em meio a uma série de técnicas de localização, a legenda do mapa também chama a atenção do leitor para um trabalho de "suposição" na representação dos rios, alertando que "não se deve confiar demasiadamente nas linhas pontilhadas" [no se debe pone gran confiaza en las líneas pontadas] (Figure 10). Novamente as representações esquemáticas têm lugar de destaque no processo de mapeamento e, em casos particulares, Fawcett acrescenta uma seta nas linhas pontilhadas para apontar, ainda que de forma bastante genérica, a direção do curso dos rios. Este é o caso da representação do rio Xapuri no mapa "Alto Acre" (Figura 11). Pode-se sugerir que parte das direções gerais das linhas pontilhadas, que ocupam áreas significativas do mapa, tenham sido traçadas a partir da troca de informação com os indígenas da região. 
Figura 9. Bolivia: La Frontiera del Norte. Percey Fawcett, 1907

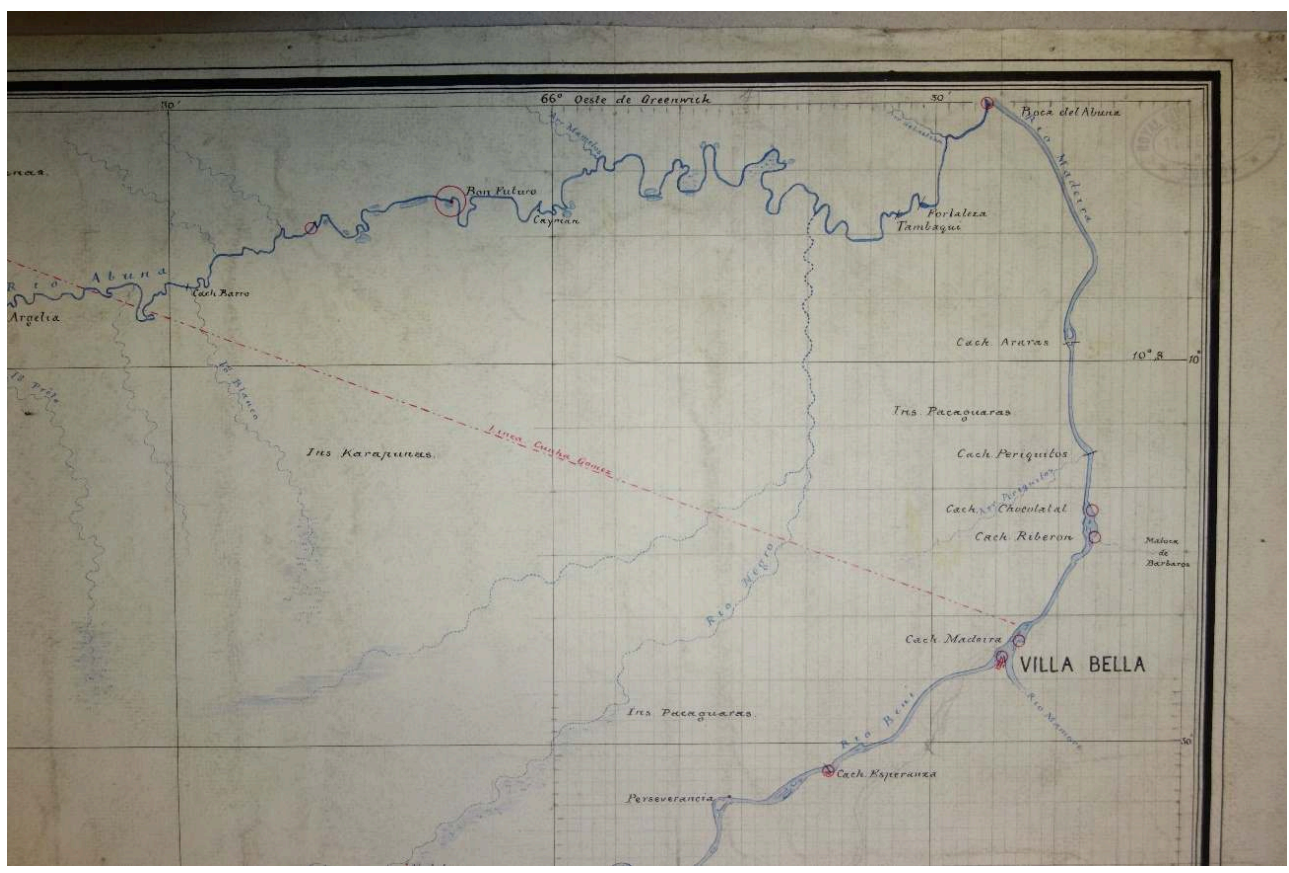

Detalhe do encontro entre o Rio Abuña e Madeira. Destaque para o limitado número de pontos georreferenciados. Escala 1:735.000

Fonte: Arquivos da Royal Geographical Society. Referência: rgs5617451 (mr Bolivia S.3). Publicado em La Paz. A. Ballivian, 1907

Figura 10. Bolivia: La Frontiera del Norte. Percey Fawcett, 1907

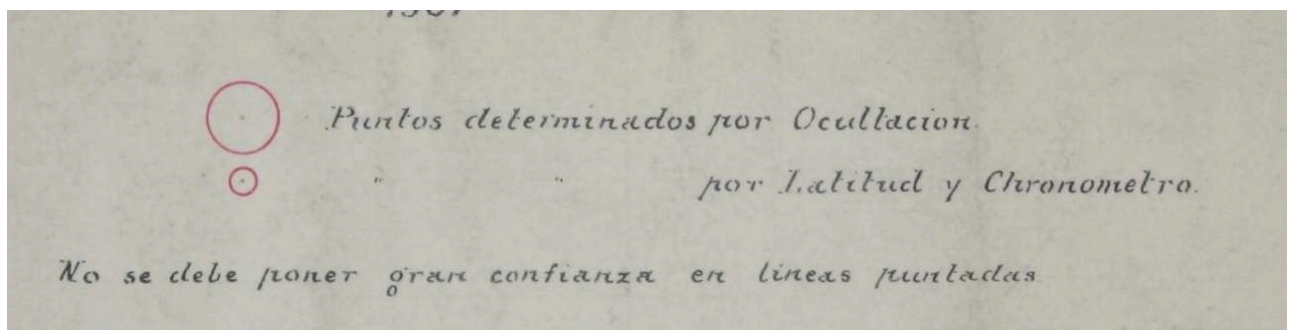

Detalhe da legenda destacando que não se pode "colocar confiaça" nas linhas pontilhadas. Escala $1: 735.000$

Fonte: Arquivos da Royal Geographical Society. Referência: rgs5617451 (mr Bolivia S.3). Publicado em La Paz. A. Ballivian, 1907 


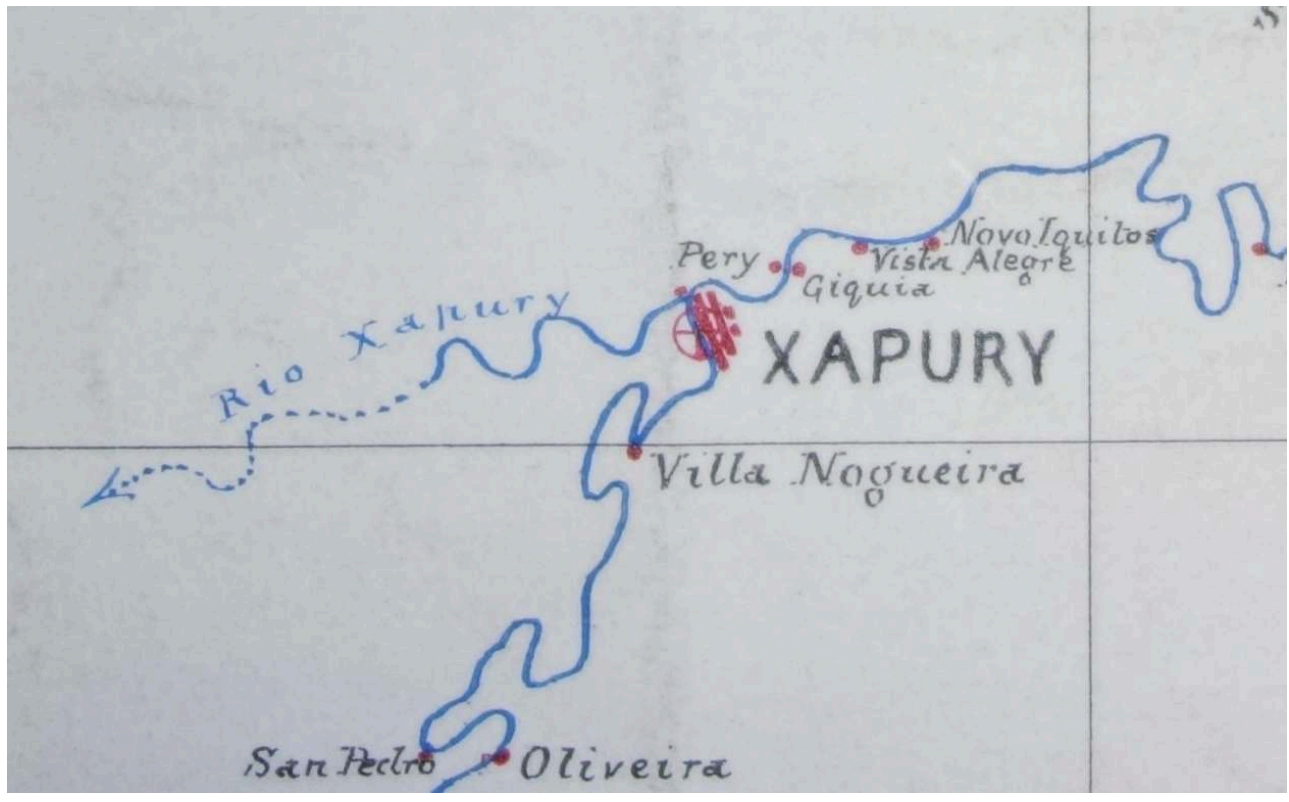

Detalhe da representação do Rio Xapuri com o uso de linhas pontilhadas e seta. Escala 1:735.000 Fonte: Arquivos da Royal Geographical Society. Referência: rgs5617451 (mr Bolivia S.3). Publicado em La Paz. A. Ballivian, 1907

Não foi simples encontrar vestígios dessas trocas de informação nos arquivos, mas algumas pistas promissoras apareceram na exploração e mapeamento do Abuña e seus afluentes. Na narrativa de Fawcett os índios aparecem muitas vezes como ameaça e perigo, a exemplo dos índios na confluência do Yaverija, que eram famosos por atacar os seringueiros. A pequena tripulação da comissão de sete membros seria, segundo Fawcett, um elemento fundamental para evitar o ataque dos índios na região (Fawcett, 2001: 83). No entanto, mesmo escapando dos índios, a febre e os mosquitos atacaram muitos membros da tripulação e, após a exploração nos rios Inquiyi e Rapirran, um dos ajudantes de Fawcett, Mr. Chalmers, retornou a Ribeiralta com cinco índios Tumupassa que estariam sofrendo de febre (Fawcett, 2001, 83). Acompanhado de "um jovem boliviano e três índios, dois dos quais subsequentemente faleceram", Fawcett seguiu até o alto Abuña e conseguiu comprar um barco pequeno por um alto preço para descer até a confluência com o Madeira (Fawcett, 1909: 181). Essa narrativa heroica, que descreve os índios ou como ameaça, ou como coadjuvantes da expedição, pode esconder trocas de informação que ocorreram durante o mapeamento.

Observando diários e escritos de Fawcett sobre essa expedição, encontrei, em meio a anotações de coordenadas, uma lista de nomes de rios com seus respectivos significados. O documento, intitulado Nomenclatura dos rios entre o Aquery e Abuña e seus significados (Figura 12), ${ }^{15}$ evidencia como os indígenas nomeavam os espaços descrevendo os seus conteúdos. O rio Iquiry (Quimbatirrã) seria aquele com abundância de uma folha larga, o rio Acre (Aquiry ou Aquery) seria o rio cheio de bastões dos quais as flechas são feitas e o rio Caipora (Mapuarrã) seria o rio do algodão. Em seus escritos, Fawcett lamenta que muitos desses nomes indígenas estejam sendo perdidos, principalmente em uma área onde "minerais estratégicos são procurados" (Fawcett, 2001: 83). A transmissão de conhecimento sobre os recursos locais é, assim, materializada nas anotações e narrativas de Fawcett, o que pode sugerir que muitas 
outras trocas de informação ocorreram no processo de produção dos mapas de fronteira.

Figura 12. Noneclature of rivers between the Aquery and Abuna and their signification. The exploration of the river Aquiry, 1906-7

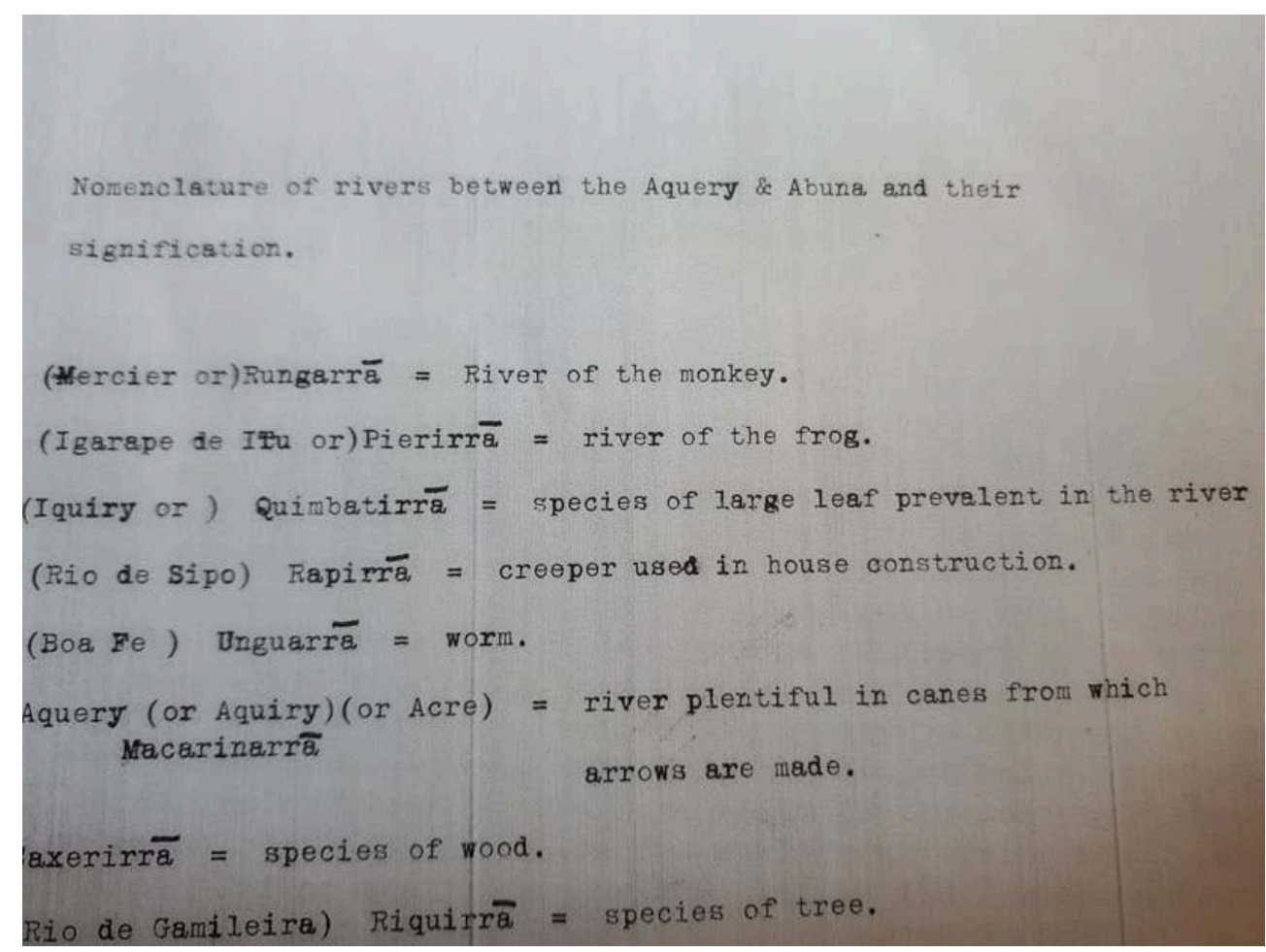

Fonte: The Fawcett Collection. Arquivos da Royal Geographical Society

Apesar de ser um dos principais objetivos da expedição, Fawcett não descreve com detalhes a subida ao rio Iquiry. Na sua narrativa, ele fala apenas que o grupo "já havia mapeado as nascentes com instrumentos inadequados" (Fawcett, 2001: 83), mas pouco discorre sobre a obtenção das coordenadas das nascentes. A forma de representação da cabeceira do Iquiry no mapa de Fawcett sugere o uso de uma função comunicativa do mapa, que localiza a cabeceira do rio por meio de uma linguagem mais pictórica e sugestiva que mimética e euclidiana (Figura 13). Traços sugerindo uma vegetação esparsa e alagadiça oferecem uma forma esquemática de localização da nascente. De qualquer forma, Fawcett considera que a exploração foi bem-sucedida, pois ajudou na "disposição do Brasil em aceitar o Alto Acre como linha de fronteira a oeste do Bahia" (Fawcett, 1909: 182). A linha de fronteira proposta após a expedição seguiria direto do rio Bahia até a nascente do Rapirran, mas o rio Iquiry desaparece do tratado, pois sua "posição foi mal compreendida" (Fawcett, 1909:182). Fawcett ainda alerta que uma comissão conjunta iria colocar os marcos de fronteira nesses rios em 1911. 
Figura 13. Bolivia: La Frontiera del Norte. Percey Fawcett, 1907

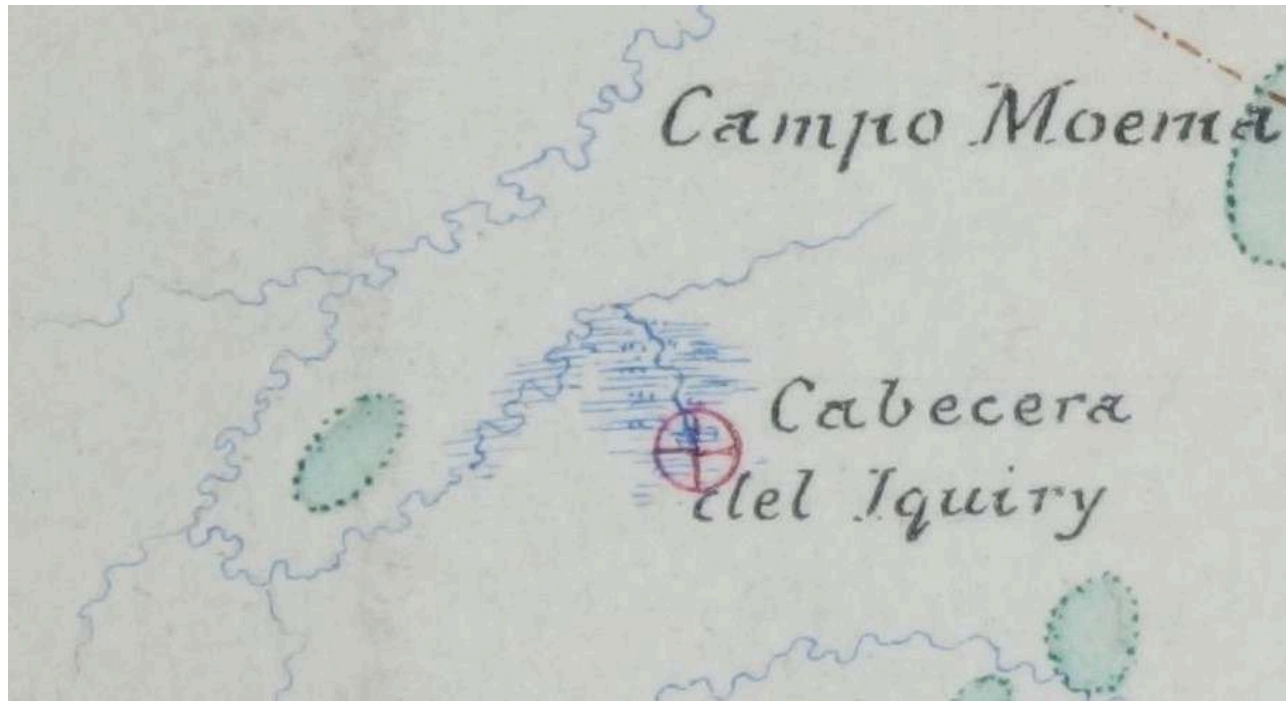

Detalhe da nascente do rio Iquiry. Escala 1:735.000

Fonte: Arquivos da Royal Geographical Society. Referência: rgs5617451 (mr Bolivia S.3). Publicado em La Paz. A. Ballivian, 1907

Ao pesquisar esta comissão posterior, comandada por Herbert Edwards, outro explorador inglês da Royal Geographical Society, juntei outras informações sobre os processos de mapeamento pelas comissões de limite no rio Abuña. Edwards afirma explicitamente que baseou sua exploração de 1911 nas informações levantadas por Fawcett em 1907, mas esta expedição parece ter sido mais robusta no uso de instrumentos e erguimento de marcos (Edwards, 1913: 115). Ao chegar às nascentes do Iquiry para demarcar a fronteira, a comissão tinha como objetivo a determinação da sua nascente principal. Para determinar a principal nascente, a equipe, como relata Edwards, entra em contato com os chefes dos grupos indígenas da vizinhança. Segundo o explorador, "os chefes indicaram-nos a nascente do riacho que eles e seus pais sempre haviam conhecido como o Iquiry, e a Comissão aceitou esse riacho e nascente como o riacho principal" (Edwards, 1913: 116). A nascente principal divergia daquela apontada por Fawcett e por isso Edwards lista os nomes dos cinco entroncamentos do Iquiry, considerando também os seus significados. Curiosamente, os significados dos rios também divergem daqueles relatados por Fawcett. O topônimo Iquiry, por exemplo, ao invés de identificar a presença de "folhas grandes", é classificado como "rio do amor".

É impossível saber o porquê de os significados coletados por Edwards em 1911 divergirem daqueles registrados por Fawcett em 1907. Talvez os índios estivessem apenas zombando dos exploradores ao inventar significados para os rios da região. Outra hipótese é que Fawcett e Edwards tenham visitado tribos diferentes. A região do Abuña com o Acre é considerada uma encruzilhada de línguas indígenas, contando com influências tanto dos troncos Tupi/Guarani e Aruaque, que circulavam no Brasil, quanto do Quéchua e outras línguas de povos que circulavam nos Andes. É natural, portanto, que os rios tivessem diferentes nomes, com diferentes significados. $O$ Rio Acre, Aquery, por exemplo, tinha muitos nomes alternativos - Macarinara ou Macarinarrã - como mostram os documentos de Fawcett e os relatos de Chandless (1869). Ao conhecer a língua, os exploradores iam conhecendo o território e suas 
qualidades, como fica evidente na detalhada descrição de Edwards sobre a relação entre os nomes e os tamanhos dos rios. A terminação "ry" significaria "rio", enquanto "ran" seriam os igarapés (Edwards, 1913: 116).

Os vestígios aqui apresentados podem parecer detalhes perdidos nos arquivos, sem importância para os processos técnicos de mapeamento dos limites internacionais. No entanto, entender as explorações geográficas enquanto transferência de informação (Lefebvre e Surun, 2008) pode abrir caminho para destacar atores silenciados que participaram ativamente da produção de conhecimento sobre as fronteiras latinoamericanas. Mesmo de forma incipiente e introdutória, os mapas e documentos aqui analisados são vestígios incontestáveis nas trocas de informação entre as comissões de limite e as populações indígenas durante as demarcações e mapeamentos realizados no início do século XX.

\section{Considerações para uma agenda de pesquisa}

Estudar as explorações e processos de mapeamento por meio de encontros culturais e fertilizações cruzadas não é tarefa fácil, pois o pesquisador muitas vezes é obrigado a se debruçar sobre pequenas notas nas cadernetas ou linhas tracejadas aparentemente desimportantes nos mapas. No entanto, esse esforço pode contribuir para arejar agendas de pesquisa, tanto na história das explorações geográficas quanto na história da cartografia, e jogar luz sobre atores frequentemente silenciados nos processos de mapeamento.

Para a história das explorações geográficas fica o desafio de se construir narrativas menos centradas no explorador, entendendo as explorações como atividades coletivas, que conectam indivíduos distintos em diferentes lugares. Situada em uma linhagem heroica de exploradores ingleses, que envolvem de Cook a Livingstone, a história de Fawcett evidencia a sobrevivência de uma "cultura da exploração" ao longo do século XX (Driver, 2001). O foco nas práticas de descolamento, proteção, alimentação e, por que não, mapeamento, podem ser um caminho interessante para problematizar a representação das explorações como dramas pessoais, que envolvem as decisões de alguns poucos indivíduos em escalas reduzidas de tempo. As trocas de informação sobre o território e a formação de práticas representacionais comuns foram mecanismos contínuos e constantes no processo de colonização. O estudo desses processos de "transferência de conhecimento" (Lebreve e Surun, 2008), "violência epistêmica" (Mignolo, 2012) ou "simbiose destrutiva" (Short, 2009), pode gerar novos olhares para os arquivos das comissões de limites que demarcaram as fronteiras amazônicas no início do século XX.

Já para a história da cartografia fica o desafio de construir narrativas menos focalizadas nos mapas enquanto representações exclusivamente geométricas e miméticas. 0 estudo das práticas de mapeamento pode contribuir para problematizar o "ideal" da cartografia, que entende o mapa "como produto de um conjunto restrito e específico de práticas" (Edney, 2020: 1). As práticas de mapeamento do Major Percy Fawcett deixaram bastante evidente como, na delimitação das fronteiras, a aplicação de técnicas de mensuração coexiste com informações "supostas" e trocas de conhecimento com a população local. A função "memorial" e "comunicativa" dos mapas, que possibilita a representação dos conteúdos do território por meio de símbolos pictóricos, inclusão de textos, uso de setas e muitas outras técnicas com origens em múltiplos lugares, foi 
recorrentemente silenciada na história da cartografia. Se buscamos abordagens contemporâneas para relativizar "o mapa" enquanto produto de uma busca constante pela precisão geométrica na representação do espaço (Edney, 2019), a pesquisa sobre histórias escondidas e trocas de conhecimento em arquivos de comissões fronteiriças na América Latina parece oferecer uma agenda de pesquisa bastante promissora.

O encontro com os arquivos do explorador Percy Fawcett na Royal Geographical Society foi uma experiência muito prazerosa e desafiadora, mas infelizmente a pesquisa teve que ser interrompida pela eclosão de uma pandemia global em março de 2020. Com a esperança de que voltaremos a frequentar arquivos físicos, espalhando documentos empoeirados em amplas mesas de trabalho, este texto foi um primeiro ensaio para um projeto mais amplo e colaborativo sobre as agências indígenas em mapeamentos fronteiriços.

\section{BIBLIOGRAFIA}

Chandless, William (1869). "Notes of a Journey up the River Juruá". Journal of the Royal Geographical Society of London, v. 39, pp. 296-311.

Cortesão, Jaime (2009 [1957] e [1971]). História do Brasil nos Velhos Mapas. Lisboa: Imprensa Nacional-Casa da Moeda.

Craib, Raymond (2017). “Cartography and Decolonization”. In: Akerman, James (ed.). Decolonizing the Map. Chicago: University of Chicago Press, pp. 11-71.

Cusicanqui, Silvia Rivera (2015). Sociología de la imagen: ensayos. Ciudad Autónoma de Buenos Aires: Tinta Limón.

Driver, Felix (2001). Geography Militant: Cultures of Exploration in an Age of Empire. London: Blackwell.

Driver, Felix; Jones, Lowri (2009). Hidden Histories of Exploration: Researching Geographical Collections, RGS-IBG/Royal Holloway.

Driver, Felix (2013). "Hidden histories made visible? Reflections on a geographical exhibition". Transactions of the Institute of British Geographers. v. 38, n. 3, pp. 420 - 435.

Edney, Matthew H. (2019). Cartography. The ideal and its history. Chicago e Londres. University of Chicago Press.

Edwards, Herbert A. (1913). "Frontier Work on the Bolivia-Brazil Boundary, 1911-12". The Geographical Journal, v. 42, n. 2, pp. 113-126.

Erbig Jr., Jeffrey Alan (2020). Where Caciques and Mapmakers Met: Border Making in EighteenthCentury South America (David J. Weber in the New Borderlands History). North Carolina: The University of North Carolina Press.

Fawcett, Percy. H. (1909). "Survey Work on the Frontier between Bolivia and Brazil". The Geographical Journal. v. 33, n. 2, pp. 181-185. 
Fawcett, Percy H. (2001). Exploration Fawcett: Journey to the Lost City of Z. Edited by Brian Fawcett [1952]. London: Weidenfeld \& Nicolson.

Holanda, Sérgio Buarque (1949). "Índios e mamelucos na expansão paulista”. Anais do Museu Paulista, Separata. v. 13, pp. 177-290.

Holanda, Sérgio Buarque de (2010 [1959]). Visão do Paraíso: os motivos edênicos no descobrimento e colonização do Brasil. São Paulo: Companhia das Letras.

Konishi, Shino; Nugent, Maria; Shellam, Tiffany (2015). "Exploration archives and indigenous histories: An Introduction”. In: Konishi, Shino; Nugent, Maria; Shellam, Tiffany (eds.). Indigenous Intermediaries: New Perspectives on Exploration archives. Sidney: Australian National University Press and Aboriginal History Inc., pp. 1-11.

Lefebvre, Camille; Surun Isabelle (2008). "Exploration et transferts de savoir: deux cartes produites par des Africains au début du 19e siècle". Mappemonde, v. 92, n.4, pp. 1-24.

Leon-Portilla Miguel (1961). The ancient Mexicans through their stories and songs. Fondo de Cultura, Mexico.

León-Portilla, Miguel (1964). El reverso de la Conquista: relaciones aztecas, mayas e incas. México: Mortiz.

MacDonald, Fraser; Withers, Charles, Withers (eds.) (2015). Geography, Technology, and Instruments of Exploration. Studies in Historical Geography. Farnham, Surrey: Ashgate.

Mignolo, Walter (2006). “Os esplendores e as misérias da 'ciência': colonialidade, geopolítica do conhecimento e pluri-versalidade epistémica”. In: Sousa Sanros, Boaventura (ed.). Conhecimento prudente para uma vida decente: um discurso sobre as ciências revisitado. São Paulo: Cortez, pp. 667-709.

Mitchell, Rose (2020). "Lines on the Map: International Boundaries”. In: Kent, Alexander James; Vervust, Soetkin; Demhardt, Imre Josef; Millea, Nick. Mapping Empires: Colonial Cartographies of Land and Sea: 7th International Symposium of the ICA Commission on the History of Cartography, 2018. Cartographic Association (ICA): Springer, pp. 207-228.

Novaes, André Reyes (2020). “Mapping Cross-Cultural Exchange: Jaime Cortesão's Dialogues and Documents on the Role of Indigenous Knowledge in Brazilian Exploration”. In: Schelhaas, Bruno; Ferretti, Federico; Novaes, André; Friedberg, Marcela. Decolonising and Internationalising Geography: Essays in the History of Contested Science. Cham: Springer, pp. 1-16.

Oliveira, Tiago Kramer (2013). "Cartografias do sertão: os mapas sertanistas no discurso histórico de Jaime Cortesão e Sergio Buarque de Holanda”. Territórios e Fronteiras (UFMT. Impresso), v. 6, n. 2, pp. $188-210$.

Radcliffe, Sarah (2017). "Decolonising geographical knowledges". Transactions of the Institute of British Geographers, v. 42, n. 3, pp. 329-333.

Ribeiro, David (2018). São Paulo capital geográfica do Brasil: a exposição do IV Centenário de São Paulo e a formação do território brasileiro na escrita histórica de Jaime Cortesão (1940 - 1960). Intermeios. São Paulo: Fapesp.

Raj, Kapil (2006). Relocating Modern Science: Circulation and the Construction of Scientific Knowledge in South Asia and Europe, 1650-1900. Basingstoke: Palgrave Macmillan.

Short, John Rennie (2009). Cartographic encounters. Indigenous peoples and the exploration of the New World. London: Reaktion Books. 


\section{ANEXOS}

\section{Documentos}

Cortesão, Jaime (1944). A Cartografia antiga e os fundamentos geográficos e préhistóricos do Brasil. Conferência. 1944. Datil, 33 f. Rio de Janeiro, 12 set. BNP/ACPC E25/38. Cortesão, Jaime (1947). O Índio: Bussola e Mapa Vivo, A Manhã, 29 de outubro, 1947, 4.

Cortesão, Jaime (1948). Origens Indígenas do Mito da Ilha-Brasil, A Manhã, 4 de janeiro, 1948, 4.

Holanda, Sergio Buarque de (1952). A Ilha Brasil. Diário Carioca. 22 de junho, 1952, 3.

National Archives: Foreign Office - FO74316.

National Archives: Foreign Office - FO 925/12053.

Royal Geographical Society: [Collection of maps by Maj. P. H. Fawcett F.R.G.S, 1907-1910.] Control Number: rgs561156.

\section{NOTAS}

1. As narrativas de Fawcett que serão utilizadas ao longo deste texto, reunidas em livros (Fawcett, 2001), artigos (Fawcett, 1909) e cadernetas de campo (Arquivos da Royal Geographical Society), foram escritas originalmente em inglês e serão traduzidas livremente pelo autor.

2. Optei aqui por traduzir o termo guesswork como "trabalho de suposição", mas achei importante citar o original em inglês pela força da palavra. Outras possibilidades de tradução para o português seriam palavras como "conjectura" ou "palpite".

3. $O$ filme The Lost City of Z ou Z: A Cidade Perdida (título no Brasil) foi dirigido e escrito por James Gray - utilizou como base o livro de mesmo título publicado pelo jornalista norte-americano David Grann em 2009. O filme foi lançado nos Estados Unidos em 21 de abril de 2017.

4. As entrevistas com o elenco do filme podem ser vistas no vídeo promocional disponível no YouTube. É interessante observar que o entrevistado que fala sobre o "propósito divino" das explorações de Fawcett é justamente David Grann, autor do livro que serviu de base para a redação do roteiro. Entrevistas Disponíveis em: https://www.youtube.com/watch? v=1_hU6psK04\&list=PLkiTYdfKQT8Jo2I3MKhOKT1JeMDKTrhl3\&index=94

5. Faço referência a James Cook (1728-1779) e David Livingstone (1813-1873), exploradores ingleses icônicos que personificam o culto a uma "cultura da exploração" no período imperial britânico (Driver, 2001).

6. A pesquisa realizada foi contemplada com bolsa de estudos financiada pela CAPES por meio do Programa de Professor Visitante no Exterior - EDITAL № 1/2019. A pesquisa também contou com o apoio da J.B. Harley Fellowship, que facilitou o acesso aos arquivos da Royal Geographical Society.

7. O catálogo da exposição está disponível gratuitamente no site da Royal Geographical Society: https://www.rgs.org/about/our-collections/online-exhibitions/hidden-histories-of-exploration/ 8. De acordo com documento disponível na Biblioteca Nacional de Portugal, Cortesão (1944) proferiu uma palestra sobre essa temática no auditório do Ministério da Educação em 1944.

9. A expressão "história dos vencidos" foi utilizada inicialmente pelo historiador mexicano LeonPortilla (1961). Após conhecer o trabalho desse autor, tomei contato com a obra de um amplo grupo de pesquisadores latino-americanos preocupados em documentar as experiências e ações das populações nativas durante a colonização. Muito antes da sistematização de abordagem póscoloniais ou decoloniais, esses autores já revelavam uma série de documentos originais sobre 
agências indígenas na colonização latino-americana, tais como: desenhos nativos, fichas criminais, testamentos, calendários e crônicas locais (Cusicanqui, 2015).

10. Ver, por exemplo, o "Mapa General del Peru, showing new boundary line between Bolivia and Brazil", 1909.

11. A informação no arquivo é fornecida em polegadas: " 44 x 32 in".

12. A informação no arquivo é fornecida em polegadas: "14 x 30 in".

13. O texto do Tratado de Petrópolis (1903) está disponível em: http://www.newmarc.com.br/ drws/tratado.pdf

14. Ver a fotografia "Portage of the Batelon at cachuela of Riberon", em Fawcett (2001: 78).

15. O documento Noneclature of rivers between the Aquery and Abuna and their signification" estava localizado na Fawcett Collection, um grupo de quatro caixas com 25 pastas contendo cartas e documentos das primeiras viagens do explorador a América Latina. Para o presente texto consultei majoritariamente os documentos The exploration of the river Aquiry, 1906-7 e Astronomical observations, Bolivia-Peru boundary and Bolivia-Brazil boundary, 1908-10.

\section{RESUMOS}

O presente artigo tem como objetivo identificar agências indígenas nos mapeamentos amazônicos conduzidos pelo explorador britânico Percy Harrison Fawcett. Atuando como engenheiro chefe da comissão boliviana de limites, Fawcett explorou o Alto Acre e o Abuña entre 1906 e 1907. Para além de uma aventura pessoal ou uma aplicação objetiva de técnicas e instrumentos, as explorações e mapeamentos conduzidos pelas comissões de limites podem ser entendidos como empreendimentos coletivos, que mobilizam uma série de atores, objetos e conhecimentos sobre o território. Na primeira seção apresento o percurso metodológico e as referências que estimularam a busca por "histórias escondidas" nos arquivos do explorador britânico, tendo os mapas e suas funções comunicativas como elementos centrais de pesquisa. Posteriormente, apresento alguns vestígios de trocas de conhecimento e agências indígenas nas primeiras explorações de Fawcett nas fronteiras entre o Brasil e a Bolívia. Cotejando narrativas exploratórias com mapas e anotações coletadas nos arquivos da Royal Geographical Society, a pesquisa buscou revelar o papel central das trocas de conhecimento e dos trabalhos de suposição na produção de mapas sobre as fronteiras latino-americanas.

This article aims to identify indigenous agencies in Amazonian mappings conducted by the British explorer Percy Harrison Fawcett. Acting as chief engineer of the Bolivian border commission, Fawcett explored the Alto Acre and Abuña between 1906 and 1907. Besides a personal adventure or an objective application of techniques and instruments, border commissions explorations and mappings can be understood as collective enterprises, which mobilize a series of actors, objects, and territorial knowledge. In the first section, I present the methodological path and the references that stimulated the search for "hidden histories" in the archives of the British explorer, considering maps and their communicative functions as central elements of research. Subsequently, I present some traces of knowledge exchanges and indigenous agencies in Fawcett's explorations at Brazil-Bolivia borders. Combining exploratory narratives with maps and notes collected at the Royal Geographical Society archives, the research sought to reveal the central role of knowledge exchanges and guesswork in the production of Latin American borders maps. 
Este artículo tiene como objetivo identificar agencias indígenas en mapeos amazónicos realizados por el explorador británico Percy Harrison Fawcett. Actuando como ingeniero jefe de la comisión de límites de Bolivia, Fawcett exploró el Alto Acre y Abuña entre 1906 y 1907. Además de una aventura personal o una aplicación objetiva de técnicas y instrumentos, se pueden comprender las exploraciones y mapeos realizados por las comisiones de limite como esfuerzos colectivos que movilizan una serie de actores, objetos y conocimientos sobre el territorio. En la primera parte del texto presento el recorrido metodológico y las referencias que estimularon la búsqueda de "historias ocultas" en los archivos del explorador británico, con los mapas y sus funciones comunicativas como elementos centrales de la investigación. Posteriormente, presento algunos rastros de intercambios de conocimiento y agencias indígenas en las primeras exploraciones de Fawcett en las fronteras entre Brasil y Bolivia. Al comparar narrativas exploratorias con mapas y notas recopiladas en los archivos de la Royal Geographical Society, la investigación buscó revelar el papel central de los intercambios de conocimiento y las conjeturas en la producción de mapas en las fronteras latinoamericanas.

Cet article vise à identifier les agences autochtones dans les cartographies amazoniennes menées par l'explorateur britannique Percy Harrison Fawcett. Agissant en tant qu'ingénieur en chef de la commission des frontières bolivienne, Fawcett a exploré l'Alto Acre et Abuña entre 1906 et 1907. Outre une aventure personnelle ou une application objective de techniques et d'instruments, les explorations et cartographies des commissions frontalières peuvent être comprises comme des entreprises collectives, qui mobilisent une série d'acteurs, d'objets et de savoirs territoriaux. Dans la première partie, je présente le parcours méthodologique et les références qui ont stimulé la recherche d '«histoires cachées» dans les archives de l'explorateur britannique, considérant les cartes et leurs fonctions communicatives comme des éléments centraux de la recherche. Par la suite, je présente quelques traces d'échanges de connaissances et d'agences autochtones dans les explorations de Fawcett aux frontières Brésil-Bolivie. Combinant des récits exploratoires avec des cartes et des notes recueillies dans les archives de la Royal Geographical Society, la recherche a cherché à révéler le rôle central des échanges de savoir et de la supposition dans la production de cartes des frontières latino-américaines.

\section{ÍNDICE}

Índice geográfico: Amazônia

Palabras claves: Percy Fawcett, historias ocultas, Fronteras Brasil-Bolivia, agencias indígenas, intercambio de conocimientos

Índice cronológico: 1906-1907

Palavras-chave: Percy Fawcett, histórias escondidas, fronteiras Brasil-Bolívia, agências indígenas, trocas de conhecimento

Keywords: Percy Fawcett, hidden stories, Brazil-Bolivia borders, indigenous agencies, knowledge exchanges

Mots-clés: Percy Fawcett, histoires caches, Frontières Brésil-Bolivie, agences autochtones, échanges de savoir 


\section{AUTOR}

\section{ANDRÉ REYES NOVAES}

Universidade do Estado do Rio de Janeiro. Departamento de Geografia Humana. bolsista Pró-

Ciência - FAPERJ.

andrereyesnovaes@gmail.com 